\title{
Acting professional: An exploration of culturally bounded norms against nonwork role referencing ${ }^{\dagger}$
}

\author{
ERIC LUIS UHLMANN ${ }^{1 *}$, EMILY HEAPHY ${ }^{2}$, SUSAN J. ASHFORD ${ }^{3}$, \\ LUKE [LEI] ZHU ${ }^{4}$ AND JEFFREY SANCHEZ-BURKS ${ }^{5 *}$ \\ ${ }^{1}$ Management and Human Resources Department, HEC Paris, Jouy-en-Josas, France \\ ${ }^{2}$ School of Management, Boston University, Boston, Massachusetts, U.S.A. \\ ${ }^{3}$ Business School, University of Michigan, Ann Arbor, Michigan, U.S.A. \\ ${ }^{4}$ Sauder School of Business, University of British Columbia, Vancouver, BC, Canada \\ ${ }^{5}$ Stephen M. Ross School of Business, University of Michigan, Ann Arbor, Michigan, U.S.A.
}

\begin{abstract}
Summary This article presents three studies examining how cross-cultural variation in assumptions about the appropriateness of referencing nonwork roles while in work settings creates consequential impressions that affect professional outcomes. Study 1 reveals a perceived norm limiting the referencing of nonwork roles at work and provides evidence that it is a U.S. norm by showing that awareness of it varies as a function of tenure living in the United States. Studies 2 and 3 examine the implications of the norm for evaluations of job candidates. Study 2 finds that U.S. but not Indian participants negatively evaluate job candidates who endorse nonwork role referencing as a strategy to create rapport and shows that this cultural difference is largest among participants most familiar with norms of professionalism, those with prior recruiting experience. Study 3 finds that corporate job recruiters from the United States negatively evaluate candidates who endorse nonwork role referencing as a means of building rapport with a potential business partner. This research underlines the importance of navigating initial interactions in culturally appropriate ways to facilitate the development of longer-term collaborations and negotiation success. Copyright (C) 2013 John Wiley \& Sons, Ltd.
\end{abstract}

Keywords: multicultural environments; professional norms; U.S. culture; role referencing; hiring evaluations

Writing to an advice column in Fortune, a reader describes working in an office space divided into grayish-beige cubicles. To cheer herself up, she decorated the cubicle with personal photographs and other artifacts that referenced her life outside of work. She confessed, however, that a co-worker felt that the workspace looked more like a room in a house than a professional office and that she should get rid of some of the mementos if she wanted to make a good impression on higher-ups. Fortune concurred with the co-worker, recommending to the reader to "clear your desk of family photos" (quoted in Fisher, 2008). Elsewhere, a U.S. website focusing on the same topic identifies "13 Ways Your Resume Can Say 'I'm Unprofessional"” and emphasizes that if it is not related to work, do not include it (Vaas, 2010, March 26).

These examples in the U.S. press highlight two organizational realities. First, they suggest that being seen as "professional" may be central to how success is defined, at least in some cultures. Second, they reveal attempts to socialize an audience to follow a tacit social norm, lest they damage their image and career. The concept of professionalism reflects, in part, normative guidelines about how to appropriately behave in a given occupational role or context (Evetts, 2003). However, although such norms appear prima facie as natural, perhaps inevitable, features of any work environment, they are rarely culture free and are thought to reflect the socially constructed prevailing ideologies of the society in which they are embedded (Branzei, Vertinsky,

*Correspondence to: Eric Luis Uhlmann, Management and Human Resources Department, HEC Paris, 78351 Jouy-en-Josas, France. E-mail: eric.luis.uhlmann@gmail.com;

Jeffrey Sanchez-Burks, Stephen M. Ross School of Business, University of Michigan, 701 Tappan Street, Ann Arbor, Michigan 48109-1234, U. S.A. E-mail: jsanchezburks@umich.edu

${ }^{\dagger}$ The first and last author shared lead author responsibilities on this paper. 
\& Camp, 2007; Gelfand \& Knight, 2005; Triandis, 1995). Thus, when moving from culture to culture and hoping to achieve important outcomes such as landing a job or getting a promotion, individuals are expected to respect a host of implicit norms that may only become apparent when they are violated (Garfinkel, 1967). Confusion about a tacit norm that may be culturally bounded is only enhanced by the growing globalization of the workplace that increasingly brings workers together across national borders where differences in cultures can result in misinterpretations and misunderstandings. A key task for individuals striving for workplace success in a new culture, then, is to discover and respect the norms of their new setting, or suffer the consequences (Imai \& Gelfand, 2009; Molinsky, 2007). The studies in this article focus on one potential culturally bounded workplace norm-that of minimizing references to one's life outside of work - and examine its consequences for perceived professionalism and evaluations of job candidates.

In this article, we review relevant research on referencing nonwork roles in work settings as well as multidisciplinary research on U.S. work values that serves as the basis for understanding norms about such referencing. At the intersection of these research streams, we derive and test hypotheses about the perceived professionalism of nonwork role referencing in the United States and its implications for a variety of dynamics in organizations.

\section{Role-referencing boundary research}

Research on the work/nonwork ${ }^{1}$ boundary has flourished over recent decades. Organizational studies have provided insights into how stress and conflict can result from participating in and attempting to balance work and nonwork roles (e.g., Edwards \& Rothbard, 1999). Yet, there is also evidence suggesting that active participation in both roles also can be a source of employee enrichment (Rothbard, 2001; Tenbrunsel, Brett, Maoz, Stroh, \& Reilly, 1995). The growing literature on the host of antecedents and outcomes associated with managing the interface between work and nonwork roles collectively illustrates the richness and centrality of the work/nonwork boundary to employees and organizations (for reviews, see Greenhaus \& Parasuraman, 1999; Kossek \& Lambert, 2005).

Traditionally, studies on the work/nonwork boundary focus on how people manage the interface between work and nonwork roles and why they choose particular strategies (Ashforth, Kreiner, \& Fugate, 2000; Lambert, 1990). For example, in navigating this boundary, people appear to vary widely in their preferences for segmenting their work and nonwork roles (Kossek, Noe, \& DeMarr, 1999). Those choosing not to segment these roles experience little difference between their home and work lives, preferring to behave similarly with their co-workers as with their neighbors. In contrast, individuals who choose to segment these roles experience them as essentially mutually exclusive categories. One manifestation of an individual's strategy for managing the work/nonwork boundary (e.g., blending the roles or keeping them separate) is their role referencing (or lack thereof).

Role referencing refers to how much a person signals his or her participation in one role while in an alternative role domain (Fisher, Bulger, \& Smith, 2009). Role referencing can be demonstrated either implicitly (e.g., by what one has in one's office space) or explicitly (e.g., in verbal comments relating to another role) (Nippert-Eng, 1996). For example, at work, some individuals minimize discussion of their personal life (e.g., a professor never making reference to her role as a bassist in a local indie rock band) and limit artifacts from this social sphere in their workspace (e.g., photographs of her band playing at a local music festival). Integration and segmentation mark the ends of a continuum, with most people falling somewhere between the two (Nippert-Eng, 1996; Olson-Buchanan \& Boswell, 2006). Of potential consequence, an individual's nonwork role-referencing practices provide cues to others from which to form impressions of the individual's reputation, identity, personality, and commitment to the organization (Ashford \& Northcraft, 1992; Elsbach, 2004; Gosling, Ko, Mannarelli, \& Morris, 2002).

Recent studies show substantive cross-cultural variation in how porous this boundary can be in people's lives and in their preferences and styles for managing transitions between work and nonwork roles (Gambles, Lewis, \& Rapoport, 2006; Komarraju, 1997; Lewis, 1997; Spector \& Allen, 2005; Yang, 2005). This article shifts its focus

\footnotetext{
${ }^{1}$ In the literature, the term "nonwork" has been used to refer broadly to those aspects of an individual's life outside their paid occupation. It could include, for example, family, recreational, or community roles.
} 
from nonwork role referencing as a personal preference to exploring the implications of violating relevant norms regarding this behavior.

\section{Culture and workways}

Cultures have been shown to exhibit specific workways (Fischer, 1989; Sumner, 1906), signature patterns of mental models and practices that embody a society's ideology about what is correct and efficient within the domain of work (Sanchez-Burks \& Lee, 2007). Examples of cultural workways include the Korean tradition of chaebol or "company familism" where companies become substitute parents for their employees (Kim, 1988), the transitivity of the Chinese networking system, guanxi (Solomon, 1999), and the Mexican relational script of simpatia, which extends warmth and sociality to acquaintances and strangers alike (Triandis, Marín, Lisansky, \& Betancourt, 1984). This article similarly focuses on "cultural workways" given the goal of understanding the culturally bounded aspects of the nonwork role-referencing norm and its implications for perceived professionalism and hiring evaluations.

One defining aspect of U.S. workways is maintaining unemotional, polite, and impersonal workplace interactions, which Sanchez-Burks (2002) referred to as Protestant Relational Ideology (PRI). This workway was first identified by Weber $(1904,1947)$, who argued that well-developed cultural norms in the U.S. regarding minimizing the personal while in the workplace can be traced to the beliefs and practices of founding Calvinist Protestant communities four centuries earlier. The original impetus for this workway was a concern for the need to put aside personal concerns to devote full attention to one's work so as to fulfill one's moral and spiritual calling. This belief resulted in a secular, yet deep-seated ideology that, as colorfully put by Hampden-Turner and Trompenaars (1993, p. 133), has produced "a split between the machine and the suburban garden."

Although the notion that a cultural imprinting of the founding communities has shaped the work values of the contemporary United States cuts across a variety of academic fields (e.g., Baker, 2007; Lipset, 1996; Norris \& Inglehart, 2004), this idea has only recently been supported by experimental laboratory evidence (for reviews, see Sanchez-Burks, 2005; Sanchez-Burks \& Uhlmann, 2013). This research established that people from the United States are less likely than members of cultures less influenced by Calvinist Protestantism (e.g., Mexico, Korea, China, India, and Thailand) to attend to and accurately recall relationship-relevant information from a work meeting (Sanchez-Burks, Nisbett, \& Ybarra, 2000), choose to join work teams whose members discuss personal matters (Sanchez-Burks et al., 2000), prefer bosses that simultaneously focus on task and social emotional concerns (Kool \& Saksena, 1988; Sinha, 1980), and form emotionally deep friendships with their co-workers (Kacperczyk, Sanchez-Burks, \& Baker, 2013).

Providing direct evidence that the influence of early Calvinist Protestant relational ideology plays a role in contemporary workplace relational norms in the United States, U.S. Methodists and Presbyterians are more likely than U.S. Catholics to ignore emotional information in work settings (Sanchez-Burks, 2002). However, it is important to emphasize that although members of specifically Calvinist Protestant denominations (i.e., Methodists and Presbyterians) are especially likely to conform to Protestant work norms, Protestant values characterize U.S. society more broadly, influencing not only devout Calvinist Protestants, but also nonProtestant and less religious individuals (Baker, 2005; Lipset, 1996; Uhlmann, Poehlman, Tannenbaum, \& Bargh, 2011).

Prior theory on PRI has drawn links between cultural values, relational practice, and boundary work that lead to testable predictions regarding the role of U.S. culture in norms regarding nonwork role referencing. PRI stipulates that impersonal workplace interactions, and therefore, the workplace norms of a culture as strongly influenced by Protestantism as that of the United States, should discourage nonwork role referencing. That is, separate from individual differences in preference for blurring of boundaries between work and nonwork, PRI suggests that there is a perceived social norm in the United States of minimizing references to the personal 
while at work. Although not all individuals may internally agree with the norm (Katz \& Allport, 1931), prior research suggests that subjectively perceived cultural norms can shape judgments and behaviors even when they are not endorsed at an individual level (Chiu, Gelfand, Yamagishi, Shteynberg, \& Wan, 2010; Prentice \& Miller, 1993).

\section{Study 1: Cultural Knowledge about Nonwork Role-Referencing Norms}

In Study 1, participants were asked to construct the work area of an employee perceived by his/her peers as unprofessional or professional; thus, this study measured participants' implicit assumptions about the nonwork role-referencing norm rather than whether they personally endorsed it. Participants rendered their mental image of the employee's workspace using a large graphic representation of an empty office along with over sixty thumbsized images of artifacts shown in pretests to reference work (e.g., file folders and paper shredder), nonwork (e.g., children's drawings, toys, and sports memorabilia), or neither context specifically (e.g., aquarium and tissue box). This methodology builds upon prior studies showing that artifacts are one means through which role-referencing behavior occurs (Nippert-Eng, 1996) and are one important way through which both personality and culture are expressed (Gosling et al., 2002; Pratt \& Rafaeli, 2005).

Hypothesis 1: Artifacts that reference nonwork roles will appear more often in renderings of an imagined office of an employee with a reputation of not being very professional compared with an employee with a reputation of being very professional.

To the extent that nonwork role referencing is a culturally bounded norm violation, we predicted that tenure in the United States would predict the tendency to associate artifacts that reference nonwork roles with an employee described as having an unprofessional reputation. The rationale for using participant's tenure in the society to examine the cultural basis of the norm is based on prior methodological techniques used in sociological and cultural psychology research (e.g., Heine \& Lehman, 2004). This approach has the advantage of allowing for a more finegrained within-culture analysis across individuals, who vary in their experience participating in the culture. Researchers measuring tenure by the number of years a respondent had lived in a particular society have shown that this indicator is associated with increasing similarity in cognition, affect, and behavior to those respondents born and raised in the culture (Benet-Martínez, Leu, Lee, \& Morris, 2002; Heine \& Lehman, 2004; Lenski, 1961; Triandis et al., 1984). Their results suggest straightforwardly that cultural knowledge is gained over time through participation in the society (Heine, Lehman, Peng, \& Greenholtz, 2002). To not confound time lived in the United States with age, this experiment used a cross-panel design with a restricted age range and controlled for age in all analyses.

Hypothesis 2: Individuals with longer tenure in the United States will be more likely to associate references to nonwork roles with a reputation as unprofessional.

Finally, the experimental design also varied the hypothetical target's gender to examine the role of gender in norms about appropriate levels of nonwork role referencing. Classic and more recent analyses suggest that men are associated with work roles and women with nonwork roles (Kanter, 1977; Lewis, 1997), which implies that the mental image of a woman's office may include artifacts that reference nonwork roles as compared with a man's office. However, women's participation in the labor force has increased dramatically since the 1970s, and women have entered historically male occupations and job categories in increasing numbers (Costa, 2000). As a result, these historic gender and role associations may no longer hold or contribute to differences in the perception of appropriate levels of nonwork role referencing. These competing perspectives on the possible role gender may play in workplace norms related to nonwork role referencing underscore the need for further data on the topic. 


\section{Method}

\section{Participants}

Ninety-five full-time employees in managerial positions enrolled in a part-time MBA program participated in this study (67 men and 28 women). The sample included 58.5 percent U.S.-born and 41.5 percent foreign-born participants. All participants for whom English was a second language were highly proficient in English (minimum Test of English as a Foreign Language score $=600$ ). The ethnic breakdown of the managers was as follows: European-American/Caucasian, 52; Asian/Asian-American, 35; Black/African-American, one; Latin/Hispanic American, four; other, three. The sample represented more than 25 industries; the largest group, 54 percent of the sample, worked in the auto industry.

\section{Materials and procedure}

To develop the experimental materials, the research team generated a list of 67 artifacts that might appear in an office (e.g., posters, pictures, and plants). To obtain artifacts symbolic of work or nonwork roles, digital color images of these items were pretested with an independent sample $(n=18)$ of people who were asked to rate the extent to which each item was or was not work related on a 5-point Likert scale $(-2=$ very work related, $-1=$ somewhat work related, $0=$ neither work nor personal, $1=$ somewhat personal, and $2=$ very personal). Twenty-seven artifacts were categorized as personal on the basis of the criterion that the mean rating was equal or greater to 1, and 14 were classified as work related on the basis of the criterion that the mean rating was equal to or less than -1 . Twenty-six were neutral, on the basis of the criterion that the mean rating was greater than -1 and less than 1. Examples of work-related artifacts included a stapler, file folder, and calculator; neutral artifacts included a plant, a landscape painting, and a wall clock; and personal artifacts included family photos, posters of movie stars, and sports equipment. These thumbnail-size images were printed on a sheet of individual self-adhesive stickers that could be removed and placed on a separate piece of paper containing an image of an office.

One of four possible descriptions of the occupant was provided. Each description was identical except for two characteristics: the target's gender (Eric or Stephanie) and reputation as unprofessional or professional. These two variables were crossed to create four versions of the employee description (unprofessional woman, unprofessional man, professional woman, and professional man) used in the between-subjects design. As an example, the following is the description for the man considered "not very professional":

Eric is a manager in his mid-thirties who has been with his company for five years. He is married and has two children. Eric's performance evaluations are consistently strong, but he is not considered very professional.

Participants were asked to complete the exercise during their organizational behavior class. They were asked to read the description of the office occupant and then attach the stickers to the office image to render what they believed that person's workspace looked like. After completing the task, participants were asked to complete demographic questions inquiring about their gender, age, nationality, and years spent in the United States. They further completed an item to measure the success of the manipulation ("Was the person occupying this office considered professional?" $(0=$ not at all, $4=$ very much $)$ ). Participant gender did not interact with the professionalism condition to predict rendering of the target person's office $(t(91)=-0.25, p=.81$, standardized $\beta=-.02)$ and is not discussed further.

\section{Results}

Table 1 displays means, standard deviations, and intercorrelations between variables involved in our analyses. 
Table 1. Mean, standard deviation, and intercorrelations.

\begin{tabular}{lrrrrrrr}
\hline Variable & \multicolumn{1}{c}{$M$} & $S D$ & 1 & 2 & 3 & 4 & 5 \\
\hline 1. Professionalism ratings & 2.34 & 1.46 & 1 & & & & \\
2. Proportion of nonwork artifacts & 0.29 & 0.17 & $-.667 * *$ & 1 & & \\
3. Target gender & 0.53 & 0.50 & .111 & -.191 & 1 & \\
4. Tenure in the United States & 20.83 & 10.63 & .006 & .175 & -.110 & 1 & \\
5. Participant gender & 0.71 & 0.46 & -.077 & -.074 & -.151 & -.030 \\
6. Participant age & 29.57 & 4.37 & -.157 & .174 & .024 & .006 & .145 \\
\hline
\end{tabular}

$* * p<.01$.

For each participant, we counted the total number of artifacts they used in their office image and then calculated the ratio of personal artifacts to the total number of artifacts to create an index that controlled for the overall number of artifacts used in rendering their image of the target's office.

\section{Manipulation check}

Regression analysis was conducted on postexperiment ratings of the level of professionalism of the office target. The regression showed that participants in the "professional" condition provided significantly higher professionalism ratings $(M=3.67, S D=0.71)$ compared with participants in the "unprofessional" condition $(M=1.20, S D=0.81)$, $t(93)=-15.53, p<.001$, standardized $\beta=-.86, d=3.36$, confirming that the manipulation was successful.

\section{Hypothesis tests}

We regressed the proportion of nonwork artifacts on the professionalism condition, participants' tenure in the United States, target gender, and the interactions between professionalism condition and target gender and between professionalism condition and participants' tenure in the United States. Participants' age was further included in the regression as a control variable. Table 2 displays the detailed results of our analyses. Supporting Hypothesis 1, a main effect of the professionalism condition indicated that a higher proportion of nonwork artifacts were associated with a target reputed to be not very professional $(M=0.40, S D=0.15)$ compared with a target reputed to be professional $(M=0.17, S D=0.07), t(87)=9.20, p<.001$, standardized $\beta=.68, d=2.03$. Supporting Hypothesis 2 , the regression further revealed a significant two-way Professionalism Condition $\times$ Tenure in the United States interaction, $t(87)=2.06, p=.04$, standardized $\beta=.16$. This interaction, shown in Figure 1, reveals that participants with greater tenure in the United States are more likely to associate nonwork role referencing with a lack of professionalism. This finding suggests that minimizing nonwork role artifacts in the workplace is a culturally bounded norm that is learned with experience living in the United States rather than a culturally universal feature of appropriate workplace behavior.

Table 2. Effect of professionalism condition on proportion of nonwork artifacts, as well as the moderating effect of tenure in the United States.

\begin{tabular}{lrr}
\hline & Standardized $\beta$ & $t$ \\
\hline Professionalism condition & 0.68 & 9.20 \\
Target gender & -0.08 & -1.00 \\
Tenure in the United States & 0.13 & 1.62 \\
Participant age & 0.06 & 0.00 \\
Professionalism Condition $\times$ Target gender & -0.03 & 0.32 \\
Professionalism Condition $\times$ Tenure in the United States & 0.16 & 0.44 \\
\hline
\end{tabular}

$N=95$. 


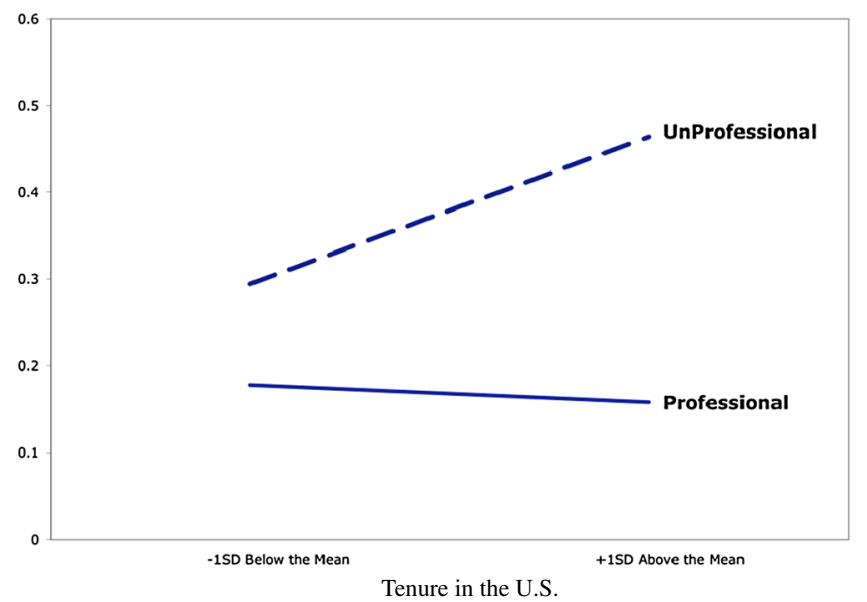

Figure 1. Proportion of artifacts that reference nonwork roles used to reconstruct a hypothetical employee's office as a function of tenure in the United States and target's reputation

\section{Discussion}

Study 1 suggests a cultural norm in the United States of minimizing references to nonwork roles in workplace contexts that is associated with perceptions of professionalism. In rendering the office of a hypothetical employee, participants imagined a greater proportion of artifacts that referenced nonwork roles in the office of an employee with a reputation as unprofessional. Given theory concerning the importance of being seen as professional in organizations (Roberts, 2005), this finding suggests one way in which individuals might communicate their professionalism or fail to do so. Further, consistent with theory suggesting that this norm may be less common among employees from other cultures, the extent to which references to nonwork roles was assumed to be associated with a lack of professionalism varied as a function of a participant's amount of experience participating in U.S. society. The longer someone had lived in the United States, the greater is the perception that nonwork role referencing was associated with an unprofessional reputation.

Importantly, the norm in the United States regarding nonwork role references appears far less extreme than an absolute prohibition. Rather, norms of professionalism and appropriateness suggest keeping references to nonwork roles to a relative minimum. Thus, a certain level of nonwork role referencing was perceived to exist even in the office of someone described as having a reputation as being "very professional" (about 17 percent of the office artifacts in this condition were presumed to reference nonwork roles, compared with 40 percent of office artifacts for a person reputed to be "not very professional").

\section{Study 2: Nonwork Role Referencing and Hiring Evaluations}

Organizational practices that control entry into organizations, such as recruitment and hiring, are often powerful mechanisms that perpetuate social norms (Martin, 2002; Schneider, 1987). Such interactions are also important arenas for individuals to establish their image as professional (Campbell \& Roberts, 2007; Molinsky, 2005; Roberts, 2005). Given this, Study 2 investigated whether participants would negatively evaluate individuals who engage in nonwork role referencing in an attempt to obtain a job offer.

Study 1 relied on participants currently employed in the United States, leaving questions about the phenomenon's cultural boundedness. To address this limitation, Study 2 compared U.S. and Indian participants' evaluations of 
individuals hoping to achieve entry into an organization. Our theoretical argument is that the relational ideology that stemmed from the cultural imprinting of Calvinist Protestantism on U.S. culture (Weber, 1905/2002; SanchezBurks, 2005) is distinct from other relational ideologies in prescribing a division between work life and social life and hence promotes relatively impersonal workplace interactions. Although Protestantism is of course only one of many religious and historical factors that have shaped U.S. work values, its influence can still be observed today (Sanchez-Burks, 2002; Sanchez-Burks \& Uhlmann, 2013). Cultures whose values are steeped in other major religious faiths (e.g., Buddhism, Islam, and Hinduism) should not exhibit the same workplace relational ideology observed in the United States. For example, unlike Calvinist Protestantism, Hinduism contains no particular proscription against socioemotional content at work. Indeed, cross-cultural research suggests that Indian society is characterized by strong relational norms both in and outside the workplace (Hofstede, 2001; Miller, Bersoff, \& Harwood, 1990; Trompenaars \& Hampden-Turner, 1997). Indians are more likely than people from the United States to view a request for help from a co-worker as an opportunity rather than a burden (Perlow \& Weeks, 2002), view helping others as a moral imperative (Miller \& Bersoff, 1992; Miller et al., 1990), and accommodate others' attempts to influence them (Savani, Morris, Naidu, Kumar, \& Berlia, 2011). Studies of organizational life in India further suggest that Indian managers tend to be knowledgeable about the personal lives of their coworkers and are often included in important ceremonies outside of work, such as weddings and funerals (Kool \& Saksena, 1988; Sinha, 1980). Moreover, researchers have described Indian "hiring and promotion practices as more 'personal' than 'impersonal"' in comparison with those of the United States (Gopalan \& Stahl, 1998, p. 36). This suggests that whereas people in the United States should negatively evaluate individuals who reference their lives outside of work in an effort to obtain a job offer, Indians will not. This pattern would provide insight into how such norms can be reinforced and instantiated in organizations via attraction/selection processes thought to create and maintain culture (Schneider, 1987).

Hypothesis 3: U.S. evaluators, but not Indian evaluators, will respond negatively to a candidate who references nonwork roles during a job interview.

If adverse consequences are in fact associated with referencing nonwork roles in U.S. organizational contexts, it would help explain why individuals would be sensitive to this norm, regardless of whether they personally endorse its existence (as shown in Study 1). Of additional interest in Study 2 is capturing variance in prior experience making recruiting decisions. People with little or no recruiting experience may be less knowledgeable about relevant norms of professionalism and thus less likely to conform to cultural prescriptions regarding nonwork role referencing. Study 2 therefore recruited a demographically diverse sample of U.S. and Indian participants varying greatly in prior experience making hiring decisions. We hypothesized that participants with such experience, who are presumably more knowledgeable about culturally specific norms of appropriate behavior during job interviews, would be more likely to exhibit relevant cultural differences in evaluations of nonwork role referencing.

Hypothesis 4: Cultural differences in responses to nonwork role referencing are greater among participants who have prior recruiting experience.

\section{Method}

\section{Participants}

Seventy-five U.S. and 110 Indian participants were recruited from Amazon.com's Mechanical Turk service in return for a small cash payment (for reviews regarding the use of MTurk for conducting research, see Buhrmester, Kwang, \& Gosling, 2011; Paolacci, Chandler, \& Ipeirotis, 2010). 
U.S. participants were 37 percent male and 63 percent female, with an average age of 36 years ( $S D=14$ years, range $=18-81$ years). Most participants from the United States had at least some advanced education: 4.1 percent did not have a high school degree, 10.8 percent had a high school education, 35.1 percent had some college education, 33.8 percent had obtained a college degree, 13.5 percent had a master's degree, and 2.7 percent had a doctoral degree. U.S. participants were on average politically moderate, with 30.3 percent identifying themselves as left wing, 43.4 percent as moderates, and 26.3 percent as right wing. ${ }^{2}$ In terms of ethnicity, 71 percent selfidentified as White, 9.2 percent as Asian, 6.6 percent as Latino, 9.2 percent as Black, and 3.9 percent as "other." A total of 74 percent of U.S. participants were currently employed, and 23 percent had prior experience in making hiring decisions.

Indian participants were 73 percent male and 27 percent female, with an average age of 29 years $(S D=8$ years, range $=20-65$ years). Similar to U.S. participants, Indian participants were relatively well educated: 0 percent lacked a high school degree, 5.5 percent had a high school education, 7.3 percent had some college education, 55.5 percent had obtained a college degree, 28.2 percent had a master's degree, and 3.6 percent had a doctoral degree. In terms of political orientation, Indians leaned slightly to the political right: 11.7 percent identified themselves as left wing, 40.5 percent as moderates, and 47.7 percent as right wing. With regard to ethnicity, 0.9 percent self-identified as White, 50 percent as Asian, 0.9 percent as Latino, 1.8 percent as Black, and 46.4 percent as Indian. A full 89 percent of Indians were employed, and 47 percent had prior experience in making hiring decisions.

\section{Design and procedures}

Participants were randomly assigned to a 2 (participant nationality: U.S. vs Indian) $\times 2$ (references-present vs references-absent) between-subjects design in which each participant evaluated a single job candidate.

All participants were asked to evaluate a candidate for a job as the representative of a rubber parts manufacturing firm (called "Hartford Industrial Works" for U.S. participants and "Chingur Industrial Works" for Indian participants). For U.S. participants, the candidate was named Nathaniel Pearson and for Indians Narayan Parthasarthy. Candidate names were selected to be similar in length and similar sounding and also to be relatively generic names based on consultations with U.S. and Indian colleagues.

In a brief interview transcript, the candidate was asked to describe the approach he would use to build rapport with a potential client. ${ }^{3}$ In the references-present condition, he answered that "After introducing myself, I would begin the meeting by making some basic small talk. I might comment on family photos, 'What a lovely family you have! How old are your kids?' and then offer some information about family members who have kids the same age." In the references-absent condition, he stated that "After introducing myself, I would begin the meeting by making some basic small talk. I might say, 'What a great office! How long have you been in this location?' If the office had a window, I might comment on the view."

After reading the scenario and interview excerpt, all participants indicated whether they would recommend hiring the applicant $(1=$ recommend against, $7=$ recommend in favor $)$. They further reported demographic information including their age, gender, education, political orientation $(1=$ very left wing, $4=$ moderate, $7=$ very right wing), employment status, and whether they had prior experience making hiring decisions. Participant gender did not interact with the nonwork role-referencing condition to predict hiring recommendations $(t(179)=0.69, p=.49$, standardized $\beta=.06$ ) and is not considered further except as a control variable. Years of experience speaking English was assessed only for Indian participants $(M=19.99$ years of English experience, $S D=9.85$ years $)$ and did not moderate their response to the nonwork role-referencing manipulation $(t(107)=0.07, p=.94$, standardized $\beta=-.007)$ and is therefore not discussed further.

\footnotetext{
${ }^{2}$ The categories of right-left rather than conservative-liberal were used for the political orientation item to better reflect the Indian political environment.

${ }^{3}$ In designing the independent variables for Studies 2 and 3, we consulted experienced recruiters and representatives of a business school recruiting office to generate applicant materials that would have face validity. From their suggestions, we set the study in the context of building rapport with a client because recruiters reported that they often struggle to discern whether job candidates are capable of interacting appropriately with potential clients.
} 


\section{Results}

Table 3 displays means, standard deviations, and intercorrelations between variables involved in our analyses.

We regressed hiring evaluations on the nonwork role-referencing condition, participant nationality, prior recruiting experience, and the two-way and three-way interactions between these variables. As expected, a significant two-way interaction emerged between participant nationality and the nonwork role-referencing condition, $t(178)=2.01, p<.05$, standardized $\beta=.17$. As shown in Table 4 , this two-way interaction remained significant when demographic variables including age, education, gender, political orientation, and employment status were included in the regression, $t(170)=2.33, p=.02$, standardized $\beta=.19$.

To unpack the observed two-way interaction, we examined the effects of nonwork role referencing on candidate evaluations separately for U.S. and Indian participants. U.S. participants provided negative evaluations of the candidate who engaged (vs did not engage) in nonwork role referencing $(M=3.28, S D=1.54$ vs $M=3.98$, $S D=1.14), t(74)=2.25, p=.03$, standardized $\beta=-.25, d=0.53$. In contrast, Indian participants reported similar candidate evaluations in the references-present and references-absent conditions $(M=4.36, S D=1.63$, and

Table 3. Mean, standard deviation, and intercorrelations.

\begin{tabular}{|c|c|c|c|c|c|c|c|c|c|c|}
\hline Variable & $M$ & $S D$ & 1 & 2 & 3 & 4 & 5 & 6 & 7 & 8 \\
\hline 1. Hiring recommendations & 4.05 & 1.55 & 1 & & & & & & & \\
\hline 2. Participant gender & 0.42 & 0.49 & -.08 & 1 & & & & & & \\
\hline 3. Participant age & 32.13 & 11.49 & $-.25^{* *}$ & $.20^{* *}$ & 1 & & & & & \\
\hline 4. Political orientation & 4.35 & 1.48 & .13 & $-.16^{*}$ & -.01 & 1 & & & & \\
\hline 5. Education & 3.90 & 0.99 & .07 & -.11 & .02 & $.17 *$ & 1 & & & \\
\hline 6. Recruiting experience & 0.63 & 0.48 & -.01 & .09 & .05 & -.03 & $-.21 * *$ & 1 & & \\
\hline $\begin{array}{l}\text { 7. Participant country of } \\
\text { origin (United States or } \\
\text { India) }\end{array}$ & 0.59 & 0.49 & $.22 * *$ & $-.36 * *$ & $-.30 * *$ & $.30 * *$ & $.33 * *$ & $-.25^{* *}$ & 1 & \\
\hline 8. Employment status & 0.17 & 0.38 & -0.07 & $.16^{*}$ & $-.21 * *$ & $-.15^{*}$ & $-.24 * *$ & .13 & $-.20 * *$ & 1 \\
\hline
\end{tabular}

$* * p<.01, * p<.05$.

Table 4. Effects of nonwork role-referencing condition on hiring recommendations, as well as the moderating effect of participants' nation of origin.

\begin{tabular}{lrrr}
\hline & Standardized & & \\
& $\beta$ & $t$ & $p$ \\
\hline Participant Country of Origin (US or India) & .14 & 1.53 & .13 \\
Nonwork role-referencing condition & -.15 & -1.82 & .07 \\
Recruiting experience & .10 & 1.30 & .20 \\
Participant Country of Origin (United States or India) $\times$ Nonwork Role-referencing Condition & .19 & 2.33 & .02 \\
Participant Country of Origin (United States or India) $\times$ Recruiting Experience & -.11 & -1.34 & .18 \\
Nonwork Role-referencing Condition $\times$ Recruiting Experience & -.02 & -0.18 & .86 \\
Participant Country of Origin (United States or India) $\times$ Nonwork Role-referencing & -.13 & -1.55 & .12 \\
Condition $\times$ Recruiting Experience & & \\
Employment status & -.10 & -1.34 & .18 \\
Participant gender & .04 & 0.55 & .58 \\
Participant age & -.25 & -3.17 & .002 \\
Education & .01 & 0.09 & .93 \\
Political orientation & .13 & 1.69 & .09 \\
\hline
\end{tabular}

$N=185$. 
$M=4.29, S D=.59$, respectively), $t(109)=0.22, p=.83$, standardized $\beta=.02, d=0.05$. This pattern of results supports Hypothesis 3.

Further analyses indicated that Americans and Indians differed only in their evaluations of the candidate who engaged in nonwork role referencing. There was no significant difference between U.S. and Indian participants in evaluations of the references-absent candidate, $t(90)=1.06, p=.29$, standardized $\beta=.11, d=0.23$. However, U.S. participants evaluated the references-present candidate more negatively than did Indian evaluators, $t(93)=3.20$, $p=.002$, standardized $\beta=.32, d=0.71$.

Candidate evaluations were measured on a 7-point scale with 4 as the neutral point on the scale. It is notable that the candidate who engaged in nonwork role referencing and was evaluated by U.S. participants represented the only case in which a candidate was rated negatively on this scale. One-sample $t$-tests comparing average hiring evaluations with the neutral scale midpoint of 4 indicated that U.S. participants rated the references-present candidate as someone they would not hire, $t(35)=2.81, p=.008, d=0.46$. In contrast, Indians provided the references-present candidate with ratings marginally above the neutral scale midpoint, $t(58)=1.68, p=.098, d=0.22$. U.S. and Indian participants both gave the references-absent candidate relatively neutral evaluations, $t<1, d=0.02$, and $t(51)=1.31$, $p=.20, d=0.18$, respectively.

The hypothesized three-way interaction between participant nationality, nonwork role referencing, and prior recruiting experience did not reach statistical significance, $t(178)=1.55, p=.12$, standardized $\beta=-.13$. However, further analyses revealed an informative pattern. No cultural difference in response to nonwork role referencing emerged among participants who lacked prior recruiting experience, $t(113)=0.42, p=.68$, standardized $\beta=.04$. In contrast, among participants who had prior experience selecting job candidates, a significant Participant Nationality $\times$ Nonwork Role Referencing interaction emerged, $t(65)=2.18, p=.03$, standardized $\beta=.29$. U.S. participants with recruiting experience negatively evaluated the candidate who engaged in nonwork role referencing $(M \mathrm{~s}=2.57$ and 3.80, SDs $=1.13$ and 1.14), $t(15)=2.20, p=.04$, standardized $\beta=-.49, d=1.12$, whereas Indian participants with recruiting experience did not $(M \mathrm{~s}=4.59$ and $4.00, S D \mathrm{~s}=1.70$ and 1.35$), t(50)=1.35, p=.18$, standardized $\beta=.19, d=0.40$ (Figure 2). Thus, the observed cultural difference in reactions to nonwork role referencing was driven entirely by participants with prior recruiting experience, providing partial support for Hypothesis 4 .

\section{Discussion}

Cultural norms regarding what is and is not appropriate behavior in a work context are enforced in part through organizational recruitment decisions (Schneider, 1987). As individuals attempt to achieve entry to organizations, they communicate their knowledge of and sensitivity to such norms. In this study, U.S. participants negatively

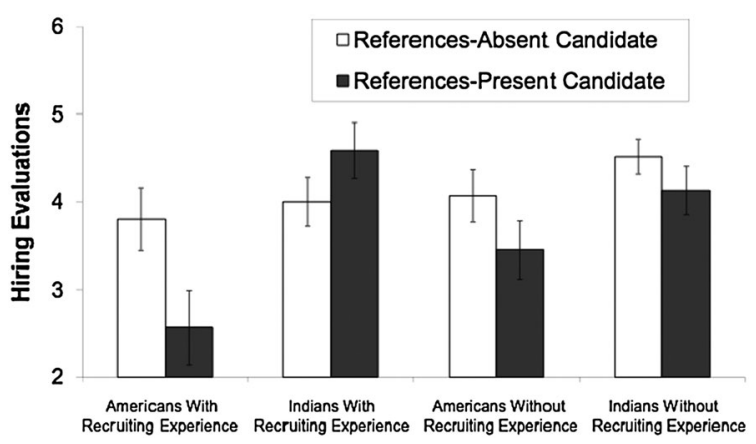

Figure 2. Candidate evaluations by participant nationality, prior recruiting experience, and whether the candidate engaged in nonwork role referencing. Error bars represent standard errors 
evaluated a job applicant who said he would engage in nonwork role referencing to build rapport with a potential business partner, whereas Indian participants did not. Job candidates' success in advancing to the next stage of the hiring process was increased when they minimized references to nonwork roles in a U.S. but not Indian context. This cultural difference was greatest with evaluators who had prior experience in making hiring decisions. Such individuals were presumably more knowledgeable about relevant norms of appropriate behavior in job interviews, leading them to evaluate norm violators more negatively. Taken together, these results suggest that the norm about nonwork role referencing differs across cultures, and its violation has consequences within U.S. culture where it is prominent.

\section{Study 3: Professional Job Recruiters}

A potential limitation of Study 2 is that although it used a demographically diverse lay sample, relatively few participants were professional managers or otherwise held positions that involved making recruitment decisions on a regular basis. Moreover, Study 2 employed a brief hiring scenario far removed from the complex set of information faced by real job recruiters. Study 3 therefore focused on corporate recruiters from U.S.-headquartered organizations across a diverse range of industries. We expected U.S. recruiters to demonstrate a fairly strong pattern of sensitivity to relevant workplace norms because they are presumably well aware of what is appropriate in professional situations. This should lead to negative reactions to individuals who engage in nonwork role referencing as a means of building rapport.

As before, participants were asked to evaluate a job candidate who either did or did not engage in nonwork role referencing. However, in this case, the application materials were more elaborate. Each set of materials contained a résumé and an essay ostensibly written by an MBA student about what they would say in a meeting with a client to build rapport with the client. To strengthen the ecological validity of the materials, we focused on an earlier stage in the recruitment process during which organizations narrow down the pool of prospective candidates using written materials, such as a job statement and résumé. The materials were presented to recruiters as an additional source of information available to evaluate job candidates that the research team was exploring in collaboration with the recruiting office. Although the candidate profiles presented in this study were neither as complex nor as complete as those a recruiter might be asked to evaluate in the case of a real job application, they provided much more detail than those in Study 2 and, together with the use of professional job recruiters as participants, allowed us to test the robustness of our effects.

\section{Method}

\section{Participants}

The sample consisted of U.S. corporate recruiters active in selecting candidates from U.S. business schools. The sample was solicited through an advertisement in an online newsletter published by a top 10 business school's career development office and invited recruiters to complete an online survey. Recruiters who did not initially respond to the online survey were later mailed a hard copy of the materials. Thirty recruiters responded to the advertisement and were entered into a lottery in which they could receive a $\$ 100$ gift certificate.

The participants were 50 percent women and 87 percent Caucasian, with a mean age of 34 years and a mean recruiting experience of 5.4 years. The participants worked for U.S.-headquartered companies representing a variety of industries: 37 percent financial, 13 percent automotive, 10 percent consumer goods, 7 percent consulting, and 7 percent manufacturing, with retail, technology, marketing, health care, entertainment, and government each representing less than 5 percent of the sample. Participants also represented a range of functions within their industries: 57 percent human resources, 10 percent marketing, and 10 percent finance, with development, relationship manager, client services, 
investment, strategy, and "other" each comprising less than 7 percent of the sample. Sixty percent of participants completed the online survey, and 40 percent completed it by mail. ${ }^{4}$

\section{Materials and procedure}

The study was introduced as research being conducted to learn more about MBA recruitment and the usefulness of a novel recruitment/evaluation technique: having candidates provide recruiters with a description of how they would handle an initial rapport-building meeting with a potential client. It was explained that this technique would provide recruiters with additional information to use in their recruitment decisions. Participants were asked to read the materials about an MBA student and then complete a survey about their impressions of the student. The materials included a résumé and a description of the hypothetical client meeting.

Participants were randomly assigned to one of two between-subjects conditions in which they rated a single job candidate who either made reference to nonwork roles (references-present condition) or did not (references-absent condition). Expanding on the manipulation used in Study 2, we manipulated reference to nonwork roles by varying the description candidates provided under the "additional information" subheading in the résumés and in the candidate's essay describing how they would handle an initial client meeting. Each résumé listed fluency in two foreign languages and membership in a professional association. In the references-present condition, the résumé included: "organized an intergenerational reunion for 100 family members" and "classic movie aficionado." In the references-absent condition, these two additional lines did not appear on the résumé. Embedded within the client meeting essay was one of two passages that did or did not make reference to nonwork roles. In the references-present condition, there were two remarks inserted into a one-page narrative description of how they would handle the client meeting. In commenting on a book on the client's bookshelf, the referencespresent candidate wrote that they would say: "My best friend recommended Senge to me first, and then I read him in graduate school. My best friend gave me a signed copy of his book for my birthday this year; we often exchange books on special occasions." In addition, in commenting on the client's desk, the references-present candidate wrote that "I might comment on family photos, "What a lovely family you have! How old are your kids?' and then offer some information about my fiancé and how I proposed to her, family members who have kids the same age, and perhaps my hobbies." In the condition with no nonwork role references, these passages were replaced with text that did not reference nonwork roles: "I read Senge's work in graduate school. What do you think of his work?" and "I might say, 'What a great office! How long have you been in this location?' If the office had a window, I might comment on the view."

The dependent measures were an overall evaluation of how qualified the candidate was for client interactions $(1=$ not at all qualified, $5=$ highly qualified $)$ and whether they would recommend the candidate for a second interview $(1=$ very strongly recommend against second interview, $6=$ very strongly recommend for second interview).

As manipulation checks, we asked recruiters how many minutes (of an hour-long meeting) they thought participants indicated they would spend on "personal information" to confirm that the manipulation was perceived accurately as varying in terms of references to personal information. To show that there were no differences in terms of rapport-building conversation, we also asked respondents to estimate the amount of time participants described spending on "small talk." That is, the experiment was designed to test for a norm against conversation specific to nonwork roles but not about small talk in general.

Finally, participants completed demographic information assessing their age, gender, years of recruiting experience, the industry they worked in, and their job at their company. Participant gender did not interact with nonwork role-referencing condition to predict the outcome measures (qualifications for client contact:

\footnotetext{
${ }^{4}$ We unintentionally failed to include the question about the recruiters' nationality and age on about half of our printed surveys (i.e., those that were distributed through the mail). Because half of our responses came from the mail surveys, we only have data on the recruiters' nationality and age for half of the sample. The career development office reviewed the sample with us, and on the basis of their knowledge of the sample, indicated that the sample was almost entirely U.S. citizens.
} 
$t(26)=-1.31, \quad p=.20, \quad$ standardized $\beta=-.23$; hiring recommendations: $t(26)=-0.24, p=.81$, standardized $\beta=-.04)$ and is not discussed further.

\section{Results}

Table 5 displays means, standard deviations, and intercorrelations between variables.

\section{Manipulation checks}

The regression analysis on the estimated number of minutes spent on personal information showed higher estimates in the references-present condition $(M=12.03, S D=8.65)$ than in the references-absent condition $(M=6.11, S D=$ $3.08), t(27)=2.42, p<.05$, standardized $\beta=.42, d=0.94$. This pattern indicates that the manipulation of conversation about personal information was successful. Moreover, the regression conducted on the estimated number of minutes spent on small talk in general did not differ by condition: references-present condition $(M=13.77, S D=7.76)$ and references-absent condition $(M=11.79, S D=7.43), t(27)=0.70, p=.49$, standardized $\beta=.13, d=0.27$. Thus, the amount of small talk was consistent across conditions; but, as intended, this small talk was seen as more personal in the references-present condition than in the references-absent condition.

\section{Qualifications for client contact}

A regression analysis was performed on respondents' ratings of the candidate's qualifications for client contact. As shown in Table 6 , there was a significant effect of condition, $t(28)=-2.30, p=.03$, standardized $\beta=-.40$, showing lower ratings in the references-present condition $(M=2.73, S D=0.59)$ than the references-absent condition $(M=3.33, S D=0.82), d=0.87$. Thus, the suggestion that a candidate would reference nonwork roles in an important client interaction significantly reduced recruiter's perceptions of their qualifications for client interactions.

Table 5. Mean, standard deviation, and intercorrelations.

\begin{tabular}{|c|c|c|c|c|c|c|c|c|c|}
\hline Variable & $M$ & $S D$ & 1 & 2 & 3 & 4 & 5 & 6 & 7 \\
\hline 1. Qualified for client contact & 3.03 & 0.76 & 1 & & & & & & \\
\hline 2. Hiring recommendations & 4.07 & 0.94 & $.570 * *$ & 1 & & & & & \\
\hline 3. Minutes spent on personal information & 9.17 & 7.13 & .028 & .196 & 1 & & & & \\
\hline 4. Minutes spent on small talk & 12.81 & 7.53 & -.169 & -.151 & .315 & 1 & & & \\
\hline 5. Participant gender & 0.50 & 0.51 & .222 & .215 & -.102 & .332 & 1 & & \\
\hline 6. Participant age & 33.72 & 8.87 & -.026 & .049 & -.226 & -.317 & -.399 & 1 & \\
\hline 7. Survey completed online & 0.40 & 0.50 & -.127 & -.352 & -.313 & .049 & .136 & N/A & 1 \\
\hline
\end{tabular}

$* * p<.01, * p<.05$.

Table 6. Effects of nonwork role referencing on qualification for client contact and hiring recommendations.

\begin{tabular}{|c|c|c|c|c|c|c|}
\hline & \multicolumn{3}{|c|}{ Qualification for client contact } & \multicolumn{3}{|c|}{ Hiring recommendation } \\
\hline & Standardized $\beta$ & $t$ & $p$ & Standardized $\beta$ & $t$ & $p$ \\
\hline Nonwork role-reference manipulation & -.40 & -2.30 & .03 & -.36 & -2.04 & .05 \\
\hline
\end{tabular}

$N=30$. 


\section{Hiring recommendations}

Second, in a test of the idea that an organization's recruitment preferences work to perpetuate a cultural norm (in this case, against references to nonwork roles in the workplace), we compared the recruiters' hiring recommendations across conditions. As shown in Table 6, the regression showed lower recommendations for a second interview in the references-present condition $(M=3.73, S D=1.10)$ than in the references-absent condition $(M=4.40, S D=.63)$, $t(28)=-2.04, p=.05$, standardized $\beta=-.36, d=0.77$.

\section{Discussion}

An important group of organizational gatekeepers, U.S. corporate recruiters, negatively evaluated candidates who indicated they would reference nonwork roles to build rapport with a potential business partner. This pattern of decision making, if common across enough organizations, would serve to reinforce the norm against role referencing in the United States. However, it is important to acknowledge the limitations of Study 3, such as the relatively small and primarily Caucasian sample, as well as the lack of an international comparison sample. These are arguably counterweighed by Study 2's much more diverse subject population and sizeable sample $(N=185)$ and direct comparison of the hiring recommendations of U.S. and Indian participants. Thus, although each possessing their own limitations, Studies 2 and 3 provide converging evidence that violating norms of U.S. professionalism by engaging in nonwork role referencing can reduce a candidate's chances of success in the hiring process.

One might argue that in a U.S. context, there are in some cases legal constraints against a recruiter asking about an applicant's non-work-related roles, potentially explaining our results. Importantly, however, in the present Studies 2 and 3, the candidate was not actually asked by the recruiter to reveal personal information about his life outside of work. Rather, he volunteered to the recruiter that he would reveal personal information to potential clients in an effort to create rapport. There are no legal constraints on voluntarily revealing such information to a job recruiter or potential client.

\section{General Discussion}

Three studies of working managers (Study 1), a demographically diverse online sample (Study 2), and corporate job recruiters (Study 3 ) provide converging evidence of a U.S. workplace norm against referencing nonwork roles. This norm reflects the prevailing workways of the larger U.S. culture, as is suggested by results showing its contrast to another country (Study 2) and that knowledge of the norm increased as a function of experience with U.S. society (Study 1). After establishing the presence of this norm and its relationship with perceived professionalism in Study 1 , we showed how violating this norm negatively affected outcomes in settings where individuals are attempting to achieve entry into organizations in Studies 2 and 3. The mere indication that a job candidate would violate this norm when attempting to build interpersonal rapport was sufficient for U.S. evaluators to assess him negatively. Indian evaluators exhibited no such negative response to candidates who engaged in nonwork role referencing.

We found that cultural differences in reactions to nonwork role referencing emerged among participants with prior experience on the recruiting end of hiring decisions, but not among those who lacked it (Study 2). This result is broadly consistent with prior research showing that, contrary to conventional wisdom suggesting that the spread of U.S.-style capitalism is globalizing workplaces worldwide, cultural differences in relational orientation across countries are often larger in work settings than in nonwork contexts (Sanchez-Burks, 2005; Sanchez-Burks \& Uhlmann, 2013). For example, people from the United States are more likely than East Asians to rely on direct communication at work, but just as likely as East Asians to rely on context-dependent communication in social situations (Sanchez-Burks et al., 2003). Here, we observe that individuals who have more experience with workplace recruiting are more likely to conform to the norms of their specific culture regarding nonwork role referencing. This suggests that within a given workplace, 
more experienced individuals such as organizational gatekeepers may be those most likely to adhere to the workplace norms of their broader culture. Future research should test this hypothesis more systematically.

\section{Implications for intercultural collaboration and negotiation}

The present studies examined how professional behavior is defined differently across cultures and did not directly examine intercultural collaborations and negotiations. However, our findings regarding culturally situated norms of professional behavior hold important implications for achieving desirable negotiation outcomes and successfully working with individuals from other cultures.

Regarding negotiation, as shown for the first time in the present research, individuals who convey a lack of awareness of norms regarding nonwork role referencing or exhibit a willingness to violate them can encounter difficulties navigating through the early stages of the hiring process leading to active job negotiations. Being perceived as professional is an important step in being asked to participate in a negotiation, which has been characterized as a critical although often overlooked aspect of negotiation (McGinn, 2006). Future research should examine how cultural differences in relational norms such as the one examined here impact negotiations at the latter stages. Each party's starting positions and reservation points are anchored on their subjective evaluations of the quality of the candidate and his or her perceived likelihood of future success in the organization. Subtle signals of a candidate's professionalism may affect the negotiating behavior of the hiring manager. If the candidate engages in nonwork role referencing, discrepancies may emerge between U.S. employers' evaluations and the candidate's self-valuation, creating a negative zone of possible agreement, or at least a much more difficult negotiation. Given research suggesting that even fleeting first impressions strongly predict later impressions (Ambady, Bernieri, \& Richeson, 2000; Ambady \& Rosenthal, 1992, 1993; Molinsky, 2005) as well as objective long-term outcomes such as career success and financial earnings (Rule \& Ambady, $2011 \mathrm{a}, \mathrm{b}$ ), the role of norm violation in early recruiting experiences is a worthy focus for future research, with its effect on specific negotiation dynamics as the important mediation path to explore.

Inadvertently violating this norm may also affect cross-cultural collaborations. Individuals perceived as unprofessional by their peers are less likely to even be selected as partners for collaborative work projects, even when their "inappropriate" acts merely reflect different cultural definitions of workplace professionalism (for empirical evidence, see Sanchez-Burks et al., 2000, 2008). In addition, long-term collaborative relationships also begin with initial impressions of whether a person would be a desirable employee, business partner, or collaborator (McGinn, 2006). These impressions are the basis for longer-term relationships (Dutton \& Heaphy, 2003; Molinsky, 2007) and as such are consequential. Thus, even though our studies examined first impressions and single interactions, perceived professionalism based on nonwork role referencing is likely to hold long-term consequences and influence interactions over time. Collaborators may generalize from this behavior to other negative behaviors associated with lack of professionalism such as failure to show up on time, follow through with commitments, or do their part on projects.

In support of this reasoning, there is evidence that PRI, the ideology that we have suggested serves as a basis for nonwork role referencing norms in the United States, plays a significant role in long-term workplace collaborations. Sanchez-Burks, Nisbett, Lee, and Ybarra (2007) demonstrated that training MBA students from the United States to be more sensitive to cultural variability in relational norms can increase their effectiveness when collaborating with individuals from other cultures. Students taught that PRI has led to distinctive workplace norms in the United States that do not necessarily translate to other cultural contexts subsequently had more successful overseas work assignments in China and Chile. Although findings such as those of Sanchez-Burks et al. (2000, 2007, 2008) are suggestive, future studies that examine whether a person perceived as unprofessional because he or she engages in "too much" nonwork role referencing is less likely to be seen as a desirable team member and co-worker in certain cultures are needed. Understanding how cultural norms regarding professionalism differ across cultures may be an important precondition for successful workplace collaborations.

Future empirical studies should directly examine the effects of nonwork role referencing during initial interactions on later stages of the job negotiation process as well as long-term collaborations in multicultural teams. Violations of 
such tacit cultural norms may account for some of the difficulties in cross-cultural collaborations and may operate outside of the full understanding of either the actor or perceiver.

\section{Implications for feedback in organizations}

One avenue for effective socialization is to provide feedback in organizations, especially for cultural newcomers. However, although there are many issues that individuals can learn about through seeking information and feedback (Ashford, 1993; Ashford \& Black, 1996), cultural norms are often difficult to discern. There is much tacit knowledge in organizations (Wagner \& Sternberg, 1985), and many norms are not explicitly stated and may in fact operate outside the complete awareness of workplace veterans and newcomers alike. It is difficult for feedback to be given or for a newcomer to even set a goal to modify their behavior if they have difficulty detecting the correct norm. Supervisors and job recruiters too may often not be able to identify specifically the origin of their negative impression of a particular employee or candidate. But when important decisions are made, the employee with the office with a higher proportion of personal effects or the candidate who discusses family matters during a negotiation does not seem "quite ready" for the next professional opportunity. Such factors may influence an evaluator's decision without their complete awareness.

\section{Men, women, and professionalism}

The extent to which role referencing was perceived to violate norms of professionalism did not differ for a male versus female target employee (Study 1). This pattern is surprising given the rich literature showing substantive differences in organizational life for men and women, particularly with respect to gender identity and issues related to work/nonwork role transitions (Bulger, Matthews, \& Hoffman, 2007; Rothbard, 2001; Rothbard, Phillips, \& Dumas, 2005). However, this pattern makes sense given the lack of any prior empirical evidence showing that women's office spaces, compared with men's office spaces, do in fact contain on average more references to nonwork roles. Instead, our results suggest that references to nonwork roles are perceived to be associated with an employee's professional reputation regardless of the employee's gender. Because this study represents an initial exploration into these links, it is our hope that it will generate more research further exploring the complex relationships between gender, reputation, and nonwork role referencing.

\section{Conclusion}

Researchers have speculated about the cultural embeddedness of role referencing (Ashforth et al., 2000; Gambles et al., 2006; Nippert-Eng, 1996). Using a cultural psychology lens, the present findings reveal how references to nonwork roles in workplace settings violate norms of U.S. professionalism. The consequences of failing to uphold this norm can be significant, among them negative evaluations from job recruiters. Within this particular society, it appears that acknowledging a life outside of work carries with it potential dangers and costs to one's reputation and access into organizations.

\section{Author biographies}

Eric Luis Uhlmann received his $\mathrm{PhD}$ from Yale University and completed his postdoctoral studies at the Kellogg School of Management. In September 2010, he joined the faculty at HEC Paris as an Assistant Professor. His research interests include gender discrimination, moral judgments, and cross-cultural management. 
Emily Heaphy is an assistant professor of Organizational Behavior at Boston University. She received her PhD from the University of Michigan. Her research focuses on what positive work relationships are and how they make a difference at work and how individuals draw on aspects of their social context to make changes in organizations. Susan (Sue) J. Ashford is the Michael and Susan Jandernoa Professor of Management and Organization at the University of Michigan. Her research focuses on individual proactivity (feedback seeking and issue selling), identity, and leadership.

Luke (Lei) Zhu is currently a PhD candidate in Organizational Behavior at the University of British Columbia. His research interests include justice, moral judgments, and psychological rationalizations. He has a Bachelor of Commerce degree from the University of Toronto.

Jeffrey Sanchez-Burks is an Associate Professor of Management and Organizations at the University of Michigan Ross School of Business in Ann Arbor. Previously, he has had visiting appointments at universities in Singapore, France, Turkey, and Russia. His research focuses on cross-cultural dynamics, creativity and curation, and social emotional intelligence. See also: www.jeffreysanchezburks.com

\section{References}

Ambady, N., Bernieri, F., \& Richeson, J. (2000). Towards a histology of social behavior: Judgmental accuracy from thin slices of behavior. In M. P. Zanna (Ed.), Advances in experimental social psychology (pp. 201-272). New York: Academic Press.

Ambady, N., \& Rosenthal, R. (1992). Thin slices of expressive behavior as predictors of interpersonal consequences: A metaanalysis. Psychological Bulletin, 111, 256-274.

Ambady, N., \& Rosenthal, R. (1993). Half a minute: Predicting teacher evaluations from thin slices of behavior and physical attractiveness. Journal of Personality and Social Psychology, 64, 431-441.

Ashford, S. J. (1993). The feedback environment: An exploratory study of cue use. Journal of Organizational Behavior, 14(3), 201-224.

Ashford, S. J., \& Black, J. S. (1996). Proactivity during organizational entry: Antecedents, tactics and outcomes. Journal of Applied Psychology, 81(2), 199-214.

Ashford, S. J., \& Northcraft, G. B. (1992). Conveying more (or less) than we realize: The role of impression-management in feedback-seeking. Organizational Behavior and Human Decision Processes, 53, 310-334.

Ashforth, B. E., Kreiner, G. E., \& Fugate, M. (2000). All in a day's work: Boundaries and micro role transitions. Academy of Management Review, 25(3), 472-491.

Baker, W. (2005). America's crisis of values. Princeton, NJ: Princeton University Press.

Baker, W. (2007). America the traditional. In R. Inglehart \& Y. Esmer (Eds.), Changing values, persisting cultures: Findings from the world values surveys. Leiden: Brill.

Benet-Martinez, V., Leu, J., Lee, F., \& Morris, M. (2002). Negotiating biculturalism: Cultural frame-switching in biculturals with oppositional vs. compatible cultural identities. Journal of Cross-Cultural Psychology, 33, 492-516.

Branzei, O., Vertinsky, I., \& Camp, R. D. II. (2007). Culture-contingent signs of trust in emergent relationships. Organizational Behavior and Human Decision Processes, 104(1), 61-82.

Buhrmester, M., Kwang, T., \& Gosling, S. D. (2011). Amazon's Mechanical Turk: A new source of inexpensive, yet highquality, data? Perspectives on Psychological Science, 6, 3-5.

Bulger, C. A., Matthews, R. A., \& Hoffman, M. E. (2007). Work and personal life boundary management: Boundary strength, work/personal life balance, and the segmentation-integration continuum. Journal of Occupational Health Psychology, 12(4), 365-375.

Campbell, S., \& Roberts, C. (2007). Migration, ethnicity and competing discourses in the job interview: Synthesizing the institutional and personal. Discourse Society, 18(3), 243-271.

Chiu, C.-Y., Gelfand, M. J., Yamagishi, T., Shteynberg, G., \& Wan, C. (2010). Intersubjective culture: The role of intersubjective perceptions in cross-cultural research. Perspectives on Psychological Science, 5, 482-493.

Costa, D. L. (2000). From mill town to board room: The rise of women's paid labor. The Journal of Economic Perspectives, 14, $101-122$.

Dutton, J. E., \& Heaphy, E. D. (2003). The power of high quality connections. In K. Cameron, J. E. Dutton, \& R. E. Quinn (Eds.), Positive organizational scholarship (pp. 263-278). San Francisco, CA: Berrett-Koehler Publishers.

Edwards, J. R., \& Rothbard, N. P. (1999). Work and family stress and well-being: An examination of person-environment fit in the work and family domains. Organizational Behavior and Human Decision Processes, 77(2), 85-129. 
Elsbach, K. D. (2004). Interpreting workplace identities: The role of office décor. Journal of Organizational Behavior, $25,99-128$. Evetts, J. (2003). The sociological analysis of professionalism: Occupational change in the modern world. International Sociology, 18, 395-415.

Fischer, D. H. (1989). Albion's seed. Oxford: Oxford University Press.

Fisher, A. (2008, February 22). Clear your desk of family photos? Retrieved from http://money.cnn.com/2008/02/22/news/economy/ clutter.fortune/index.htm

Fisher, G. G., Bulger, C. A., \& Smith, C. S. (2009). Beyond work and family: A measure of work/non-work interference and enhancement. Journal of Occupational Health Psychology, 14(4), 441-456.

Gambles, R., Lewis, S., \& Rapoport, R. (2006). The myth of work-life balance: The challenge of our time for men, women and societies. Chichester: Wiley.

Garfinkel, H. (1967). Studies in ethnomethodology. Englewood Cliffs, NJ: Prentice-Hall.

Gelfand, M. J., \& Knight, A. P. (2005). Cross-cultural perspectives on work-family conflict. In S. A. Y. Poelmans (Ed.), Work and family: An international research perspective (pp. 401-414). Mahwah, NJ: Lawrence Erlbaum Associates.

Gopalan, S., \& Stahl, A. (1998). Application of American management theories and practices to the Indian business environment: Understanding the impact of national culture. American Business Review, 16(2), 30-41.

Gosling, S. D., Ko, S. J., Mannarelli, T., \& Morris, M. E. (2002). A room with a cue: Personality judgments based on offices and bedrooms. Journal of Personality and Social Psychology, 82(3), 379-398.

Greenhaus, J. H., \& Parasuraman, S. (1999). Research on work, family and gender: Current status and future directions. In G. N. Powell (Ed.), Handbook of gender \& work. Thousand Oaks, CA: Sage.

Hampden-Turner, C., \& Trompenaars, F. (1993). The seven cultures of capitalism: Value systems for creating wealth in the United States, Japan, Germany, France, Britain, Sweden and the Netherlands. New York, NY: Doubleday.

Heine, S. J., \& Lehman, D. R. (2004). Move the body, change the self: Acculturative effects on the self-concept. In M. Schaller \& C. Crandall (Eds.), Psychological foundations of culture (pp. 305-331). Mahwah, NJ: Erlbaum Associates.

Heine, S. J., Lehman, D. R., Peng, K., \& Greenholtz, J. (2002). What's wrong with cross-cultural comparisons of subjective Likert scales?: The reference-group effect. Journal of Personality and Social Psychology, 82, 903-918.

Hofstede, G. (2001). Culture's consequences: Comparing values, behaviors, institutions, and organizations across nations. Thousand Oaks, CA: Sage Publications.

Imai, L., \& Gelfand, M. J. (2009). Culture and negotiation: Interdisciplinary perspectives. In R. S. Bhagat, \& R. M. Steers (Eds.), Handbook of culture, organizations, and work. Cambridge: Cambridge University Press.

Kacperczyk, A., Sanchez-Burks, J., \& Baker, W. (2013). Social isolation at work? A longitudinal and cross-cultural analysis of coworker multiplexity and their social benefits (Unpublished Working Paper No. 4535-341). Ann Arbor, MI: Ross School of Business.

Kanter, R. M. (1977). Work and family in the United States: A critical review and agenda for research and policy. New York, NY: Russell Sage Foundation.

Katz, D., \& Allport, F. H. (1931). Student attitudes. Syracuse, NY: Craftsman.

Kim, S. U. (1988). The role of social values and competitiveness in economic growth: With special reference to Korea. In D. Sinha \& H. S. R. Kao (Eds.), Social values and development: Asian perspectives (pp. 76-92). New Delhi: Sage.

Komarraju, M. (1997). The work-family interface in India. In S. Parasuraman, \& J. H. Greenhaus (Eds.), Integrating work and family: Challenges and choices for a changing world (pp. 104-114). Westport, CT: Quorum Books.

Kool, R., \& Saksena, N. K. (1988). Leadership styles and its effectiveness among Indian executives. Indian Journal of Applied Psychology, 26(1), 9-15.

Kossek, E. E., \& Lambert, S. J. (2005). Work and life integration: Organizational, cultural and individual perspectives. Mahwah, NJ: Erlbaum Associates.

Kossek, E. E., Noe, R., \& DeMarr, B. (1999). Work-family role synthesis: Individual, family and organizational determinants. International Journal of Conflict Management, 10, 102-129.

Lambert, S. J. (1990). Processes linking work and family: A critical review and research agenda. Human Relations, 43, $239-257$. Lenski, G. (1961). The religious factor. New York: Anchor Books.

Lewis, S. (1997). An international perspective on work-family issues. In S. Parasuraman, \& J. H. Greenhaus (Eds.), Integrating work and family: Challenges and choices for a changing world (pp. 91-103). Westport, CT: Quorum Books.

Lipset, S. M. (1996). American exceptionalism: A double edged sword. New York, NY: W.W. Norton \& Co.

Martin, J. (2002). Organizational culture: Mapping the terrain. Thousand Oaks, CA: Sage.

McGinn, K. L. (2006). Relationships and negotiations in context. In L. Thompson (Ed.), Frontiers of social psychology: Negotiation theory and research (pp. 129-144). New York: Psychological Press.

Miller, J. G., \& Bersoff, D. M. (1992). Culture and moral judgment: How are conflicts between justice and interpersonal responsibilities resolved? Journal of Personality and Social Psychology, 62, 541-554.

Miller, J. G., Bersoff, D. M., \& Harwood, R. L. (1990). Perceptions of social responsibilities in India and in the United States: Moral imperatives or personal decisions? Journal of Personality and Social Psychology, 58, 33-47. 
Molinsky, A. L. (2005). Language fluency and the evaluation of cultural faux pas: The case of Russians interviewing for jobs in the United States. Social Psychology Quarterly, 68, 103-120.

Molinsky, A. L. (2007). Cross-cultural code-switching: The psychological challenges of adapting behavior in foreign cultural interactions. Academy of Management Review, 32, 622-640.

Nippert-Eng, C. E. (1996). Home and work: Negotiating boundaries of everyday life. Chicago, IL: University of Chicago Press. Norris, P., \& Inglehart, R. (2004). Sacred and secular: Religion and politics worldwide. New York, NY: Cambridge University Press.

Olson-Buchanan, J. B., \& Boswell, W. R. (2006). Blurring boundaries: Correlates of integration and segmentation between work and non-work. Journal of Vocational Behavior, 68, 432-445.

Paolacci, G., Chandler, J., \& Ipeirotis, P. G. (2010). Running experiments on Amazon Mechanical Turk. Judgment and Decision Making, 5, 411-419.

Perlow, L., \& Weeks, J. (2002). Who's helping whom? Layers of culture and workplace behavior. Journal of Organizational Behavior, 23(4), 345-361.

Pratt, M., \& Rafaeli, A. (2005). Artifacts and organizations. New York: Erlbaum Associates.

Prentice, D. A., \& Miller, D. T. (1993). Pluralistic ignorance and alcohol use on campus: Some consequences of misperceiving the social norm. Journal of Personality and Social Psychology, 64, 243-256.

Roberts, L. M. (2005). Changing faces: Professional image construction in diverse organizational settings. The Academy of Management Review, 30(4), 685-711.

Rothbard, N. R. (2001). Enriching or depleting? The dynamics of engagement in work and family roles. Administrative Science Quarterly, 46, 655-684.

Rothbard, N. R., Phillips, K., \& Dumas, T. (2005). Multiple roles: Work-family policies and individual's desires for segmentation. Organization Science, 16, 243-258.

Rule, N. O., \& Ambady, N. (2011a). Face and fortune: Inferences of personality from managing partners' faces predict their firms' financial success. The Leadership Quarterly, 22, 690-696.

Rule, N. O., \& Ambady, N. (2011b). Judgments of power from college yearbook photos and later career success. Social Psychological and Personality Science, 2, 154-158.

Sanchez-Burks, J. (2002). Protestant Relational Ideology and (in) attention to relational cues in work settings. Journal of Personality and Social Psychology, 83(4), 919-929.

Sanchez-Burks, J. (2005). Protestant Relational Ideology: The cognitive underpinnings and organizational implications of an American anomaly. Research in Organizational Behavior, 26, 265-305.

Sanchez-Burks, J., \& Lee, F. (2007). Cultural psychology of workways. In D. Cohen, \& S. Kitayama (Eds.), Handbook of cultural psychology (pp. 346-369). New York, NY: Guilford Press.

Sanchez-Burks, J., Lee, F., Choi, I., Nisbett, R., Zhao, S., \& Jasook, K. (2003). Conversing across cultures: East-west communication styles in work and non-work contexts. Journal of Personality and Social Psychology, 85, 363-372.

Sanchez-Burks, J., Neuman, E., Ybarra, O., Kopelman, S., Goh, K., \& Park, H. (2008). Cultural folk wisdom about relationship conflict. Negotiation and Conflict Management Research, 1, 55-78.

Sanchez-Burks, J., Nisbett, R., Lee, F., \& Ybarra, O. (2007). Intercultural training based on a theory of relational ideology. Basic and Applied Social Psychology, 29, 257-268.

Sanchez-Burks, J., Nisbett, R., \& Ybarra, O. (2000). Cultural styles, relational schemas and prejudice against outgroups. Journal of Personality and Social Psychology, 79(2), 174-189.

Sanchez-Burks, J., \& Uhlmann, E. L. (2013). Outlier nation: The cultural psychology of American workways. In M. Yuki \& M. Brewer (Eds.), Frontiers of culture and psychology: Culture and group processes. New York, NY: Oxford University Press.

Savani, K., Morris, M. W., Naidu, N. V. R., Kumar, S., \& Berlia, N. V. (2011). Cultural conditioning: Understanding interpersonal accommodation in India and the United States in terms of the modal characteristics of interpersonal influence situations. Journal of Personality and Social Psychology, 100(1), 84-102.

Schneider, B. (1987). The people make the place. Personnel Psychology, 40(3), 437-453.

Sinha, J. B. (1980). Nurturant task leader. New Delhi, India: Concept Publishing Company.

Solomon, R. H. (1999). Chinese negotiating behavior: Pursuing interests through 'old friends'. Washington, DC: United States Institute of Peace Press.

Spector, P. E., \& Allen, T. D. (2005). An international comparative study of work-family stress and occupational strain. In S. A. Y. Poelmans (Ed.), Work and family: An international research perspective (pp. 71-84). Mahwah, NJ: Erlbaum Associates.

Sumner, W. (1906). Folkways: A study of the sociological importance of usages, manners, customs, mores, and morals. Boston: Ginn and Co.

Tenbrunsel, A. E., Brett, J. M., Maoz, E., Stroh, L. K., \& Reilly, A. H. (1995). Dynamic and static work-family relationships. Organizational Behavior and Human Decision Processes, 63(3), 233-246.

Triandis, H. C. (1995). Individualism and collectivism. Boulder, CO: Westview Press.

Triandis, H. C., Marín, G., Lisansky, J., \& Betancourt, H. (1984). Simpatía as a cultural script of Hispanics. Journal of Personality and Social Psychology, 47(6), 1363-1375. 
Trompenaars, F., \& Hampden-Turner, C. (1997). Riding the waves of culture: Understanding diversity in global business. New York, NY: McGraw-Hill.

Uhlmann, E. L., Poehlman, T. A., Tannenbaum, D., \& Bargh, J. A. (2011). Implicit Puritanism in American moral cognition. Journal of Experimental Social Psychology, 47, 312-320.

Vaas, L. (2010, March 26). 13 ways your resume can say 'I'm unprofessional'. Retrieved from http://www.theladders.com/ career-advice/13-ways-your-resume-can-say-im-unprofessional

Wagner, R. K., \& Sternberg, R. J. (1985). Practical intelligence in real-world pursuits: The role of tacit knowledge. Journal of Personality and Social Psychology, 49, 436-458.

Weber, M. (1904). Protestant ethic and the spirit of capitalism. Winchester, MA: Allen \& Unwin.

Weber, M. (1905/2002). The Protestant ethic and the spirit of capitalism. New York: Penguin.

Weber, M. (1947). The theory of social and economic organization. New York, NY: The Free Press.

Yang, N. (2005). Individualism-collectivism and work-family interfaces: A Sino-U.S. comparison. In S. Poelmans (Ed.), Work and family: An international perspective (pp. 287-318). Mahwah, NJ: Erlbaum Associates. 